Obviously there is strong competition for limited Government resources. But need such an unpalatable course of action have been so inflexible, particularly where postponement will cause considerable local hardship? The Health Departments have made health centre development a major feature of their planning, almost giving the impression that money was no object. Such a sudden policy reversal is bound to make doctors more cautious about entering into negotiations for health centres in future. Furthermore, this damage to the profession's confidence comes at a time when experience suggests that health centres are an asset to patients and doctors without so far compromising the latter's professional freedom. The Government may argue that it is only a postponement and that it did not foresee how successful-and therefore how financially demanding-its policy would be. Such an argument will be small comfort to those faced with the practical consequences of this sudden retrenchment.

\footnotetext{
${ }^{1}$ Department of Health and Social Security Annual Report 1971, Cmnd. 5019. London, H.M.S.O., 1972.

${ }^{2}$ Department of Health and Social Security Annual Report, 1972, Cmnd.

3 British Medical fournal Supplement, 1973, 3, 16.
}

\section{Rheumatoid Arthritis of Temporo-mandibular Joint}

Sir Archibald Garrod, who introduced the term rheumatoid arthritis, emphasized the frequency of the disease in the temporo-mandibular joints. In the 19th century other reports indicated a high incidence, yet in the early part of this century it is hardly mentioned. In 1941 a clinical study suggested an incidence of $51 \% .^{1}$ From then, though reports have noted a varying incidence, it does not seem to have made any great impact.

This may be because few patients spontaneously complain of it or because the severity of lesions in other joints, particularly of the lower limbs and hands, has overshadowed pain in the jaw, or the incidence of visceral lesions has been considered more important. A post-mortem study ${ }^{2}$ on ten cases of severe widespread rheumatoid arthritis showed it to be present in seven. In contrast, disease of temporomandibular joints and the jaw has been emphasized in juvenile chronic polyarthritis. ${ }^{3}$ It is of importance in this particular disorder because it is apt to lead to bone fusion, which impedes biting and so impairs the patients ability to eat. It can also give rise to difficulty during anaesthesia. There may be an associated foreshortening of the lower jaw as a growth defect, brachygnathia.4

A recent study suggests this joint is commonly involved in adult rheumatoid arthritis. 5 One hundred patients, 77 female and 23 male, suffering from rheumatoid arthritis were compared with 39 patients with generalized osteoarthrosis and 56 apparently normal people. The patients were seen consecutively at a specialist rheumatological centre, and thus represented the more severe types of case. Their mean age was 42 years. The clinical examination included deviation of the mandible from the midline during opening and closing movements of the mouth, limitation of opening of the mouth, subjective symptoms of stiffness, joint crepitus on palpation, click, pain in or referred from the joint, tenderness of the joint on palpation, and swelling of soft tissue.

One or more clinical abnormalities were present in $71 \%$ of the patients with rheumatoid arthritis compared with $41 \%$ of the controls. Radiological abnormalities thought to be characteristics of rheumatoid arthritis were present in $79 \%$ compared with $33 \%$ of the controls. There was good agreement between clinical symptoms and radiological change, but severe disability was uncommon. Surface and pocket erosion, flattening, and marginal proliferations correlated well with limitation of opening, stiffness, crepitus, referred pain, and tenderness on biting. No ankylosis was reported.

In assessing the condition of patients complaining of pain in the temporo-mandibular joint the most important physical signs would appear to be pain in the joint, pain on biting, referred pain, tenderness or crepitus on palpation over the joint, and limitation of opening of the mouth. It would seem unlikely that patients with only mild rheumatoid disease present with involvement of the temporo-mandibular joints. But it should be borne in mind that the temporomandibular joint is commonly the site of an unusual osetoarthrosis in middle-aged women, which occurs without involvement of other joints. ${ }^{6}$ The symptoms are similar to those found in rheumatoid arthritis. Unlike osteo-arthrosis in other joints, this runs a clinical course of one to three years and is usually followed by natural regression of symptoms, ending with little permanent disability. Occasionally surgical treatment will be required. 7 The importance of recognizing this unusual form of osteoarthropathy of the mandibular condyle is because of its frequent presentation in women at an age when rheumatoid arthritis is fairly common. There is no systemic disturbance, no other joints show active inflammatory arthritis, the erythrocyte sedimentation rate is usually normal, and the tests for rheumatoid factor are negative. It is of course possible that rheumatoid arthritis could start in the temporo-mandibular joint, but this should not be entertained unless there are other features to suggest it. The high incidence of clinical and radiological change in the controls in the survey 5 indicated the frequency of abnormality in the temporo-mandibular joint in the general population.

In the management of temporo-mandibular arthropathy the usual anti-inflammatory drugs are helpful. If there is crepitus on palpation associated with severe pain, a course of short-wave diathermy may be valuable. When there is obvious soft-tissue swelling and pain on attempted movement, application of ice over the inflamed joint mav relieve the patient. If symptoms persist, an intra-articular iniection of a corticosteroid preparation usually suffices to dispel them. A careful technique is required, and a small dose of long-acting preparation is introduced, preferably after an auriculotemporal nerve block. Excision of the mandibular condvle is rarely reauired. But the same is not true of juvenile chronic polyarthritis with bonv fusion of the temporo-mandibular joint. Then surgery will be required. ${ }^{8}$

\footnotetext{
1 Russell, L. A., Bayless, T. B., fournal of the American Dental Association, $1941,28,533$.

2 Blackwood, H. J. J., British Dental fournal, 1963, 115, 317

Sairanen, E., and Helminen-Pakkala, E., Acta Radiologica, 1966, 4, 86. Laaksonen, A. L., Acta Paediatrica Scandinavica, 1966, supplement No. 166.

s Chalmers, I. M., and Blair, G. S., Quarterly fournal of Medicine, 1973, 42, 369.

- Toller, P. A., British Dental Fournal, 1973, 134, 223.

7 Henny, F. A., and Baldridge, O. L., Fournal of Oral Surgery, 1957, 15, 24.

8 Bornstein, L. A., and Ramon, Y., British fournal of Plastic Surgery, 1963, 16. 95 .
} 